\title{
Macrocyclic Gadolinium-Based Contrast Agents Do Not Cause Hyperintensity in the Dentate Nucleus
}

W e wish to comment on the December 2015 article of Ramalho et $\mathrm{al}^{1}$ entitled "Gadolinium-Based Contrast Agent Accumulation and Toxicity: An Update" in the American Journal of Neuroradiology.

First, the authors introduced the study of Stojanov et $\mathrm{al}^{2}{ }^{2}$ in which gadobutrol (Gadavist; Bayer Schering Pharma, Berlin, Germany) was purported to cause hyperintensity in the dentate nucleus. However, this report lacks evidence because no hyperintensity in the dentate nucleus on T1WI could be noted in their presented figure, despite being seen in all other previous reports. ${ }^{3}$ In addition, Radbruch et $\mathrm{al}^{4}$ performed a replication study in which gadobutrol showed no correlation with hyperintensity in the dentate nucleus on T1WI. An animal study ${ }^{5}$ also denied the association between gadobutrol and hyperintensity in the dentate nucleus on T1WI. These results demonstrated that macrocyclic gadolinium-based contrast agents do not cause hyperintensity in the dentate nucleus.

Second, our group ${ }^{6}$ evaluated gadolinium deposition in the dentate nucleus, internal segment of the globus pallidus, frontal cortical lobe, white matter of the frontal lobe, and cerebral white matter. McDonald et $\mathrm{al}^{7}$ evaluated gadolinium deposition in the dentate nucleus, globus pallidus, thalamus, and pons. In addition, they confirmed the presence of extensive gadolinium deposits prominently clustered within the endothelial wall by using $\mathrm{x}$-ray microanalysis. In the article by Ramalho et al, our work is mistaken for the great work of McDonald et al.

These 2 articles ${ }^{6,7}$ were published at almost the same time. The submission of our article on November 20, 2014, was earlier than that of McDonald et al, ${ }^{7}$ submitted on January 5, 2015, but the acceptance was on March 24, 2015-namely, later than the acceptance of the work of McDonald et al on February 12, 2015. Our work and the work of McDonald et al progressed independently, and the work of McDonald et al was published a little earlier than our article.

\section{REFERENCES}

1. Ramalho J, Semelka RC, Ramalho M, et al. Gadolinium-based contrast agent accumulation and toxicity: an update. AJNR Am J Neuroradiol 2015 Dec 10. [Epub ahead of print] CrossRef Medline

2. Stojanov DA, Aracki-Trenkic A, Vojinovic S, et al. Increasing signal intensity within the dentate nucleus and globus pallidus on unenhanced T1W magnetic resonance images in patients with relapsingremitting multiple sclerosis: correlation with cumulative dose of a macrocyclic gadolinium-based contrast agent, gadobutrol. Eur Radiol 2016;26:807-15 CrossRef Medline

3. Kanda $\mathrm{T}$, Oba $\mathrm{H}$, Toyoda $\mathrm{K}$, et al. Brain gadolinium deposition after administration of gadolinium-based contrast agents. Jpn J Radiol 2016;34:3-9 CrossRef Medline

4. Radbruch A, Weberling LD, Kieslich PJ, et al. High-signal intensity in the dentate nucleus and globus pallidus on unenhanced T1weighted images: evaluation of the macrocyclic gadolinium-based contrast agent gadobutrol. Invest Radiol 2015;50:805-10 CrossRef Medline

5. Jost G, Lenhard DC, Sieber MA, et al. Signal increase on unenhanced T1-weighted images in the rat brain after repeated, extended doses of gadolinium-based contrast agents: comparison of linear and macrocyclic agents. Invest Radiol 2016;51:83-89 CrossRef Medline

6. Kanda T, Fukusato T, Matsuda M, et al. Gadolinium-based contrast agent accumulates in the brain even in subjects without severe renal dysfunction: evaluation of autopsy brain specimens with inductively coupled plasma mass spectroscopy. Radiology 2015;276: 228-32 CrossRef Medline

7. McDonald RJ, McDonald JS, Kallmes DF, et al. Intracranial gadolinium deposition after contrast-enhanced MR imaging. Radiology 2015;275:772-82 CrossRef Medline

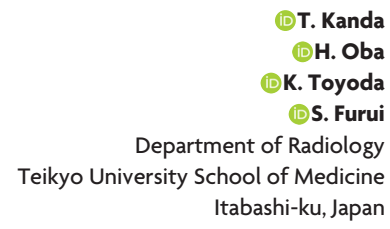

